\title{
Melatonin synthesis pathway: circadian regulation of the genes encoding the key enzymes in the chicken pineal gland and retina
}

\author{
Marianne Bernard ${ }^{\mathrm{a} *}$, Jérôme Guerlottéa ${ }^{\mathrm{a}}$ Pierre Grève ${ }^{\mathrm{a}}$, \\ Aline Gréchez-Cassiau ${ }^{\mathrm{a}}$, Michael P. Iuvone ${ }^{\mathrm{b}}$, Martin Zatz ${ }^{\mathrm{c}}$, \\ Nelson W. Chong ${ }^{d}$, David C. Klein ${ }^{\mathrm{d}}$, Pierre Voisin ${ }^{\mathrm{a}}$ \\ ${ }^{a}$ Laboratoire de neuroendocrinologie, UMR CNRS 6558, 40, avenue du Recteur-Pineau, \\ 86022 Poitiers cedex, France \\ ${ }^{b}$ Department of Pharmacology, Emory University School of Medicine, Atlanta, GA 30322, USA \\ ${ }^{c}$ Laboratory of Cellular and Molecular Regulation, National Institute of Mental Health, \\ National Institutes of Health, Bethesda, MD 20892-4480, USA \\ ${ }^{d}$ Laboratory of Developmental Neurobiology, Section of Neuroendocrinology, \\ National Institute of Child Health and Human Development, National Institutes of Health, \\ Bethesda, MD 20892-4480, USA
}

(Received 1 March 1999; accepted 19 March 1999)

\begin{abstract}
The mRNAs encoding three enzymes of the melatonin synthesis pathway (tryptophan hydroxylase (TPH), arylalkylamine- $N$-acetyltransferase (AANAT) and hydroxyindole- $O$-methyltransferase (HIOMT)) are expressed with a day/night rhythm in the chicken pineal gland and retina. TPH and AANAT mRNA levels reach their peak at night. HIOMT mRNA levels peak at night in the retina, but during the day in the pineal gland. In this tissue, the rhythm of TPH, AANAT and HIOMT mRNA levels persisted in constant darkness (DD), both in vivo and in vitro, indicating that the three genes are controlled by the circadian oscillator of the chicken pineal. In the retina, the rhythms of TPH and AANAT mRNA levels also persisted in DD in vivo, suggesting that they are driven by a circadian oscillator. In contrast, the rhythm of HIOMT mRNA in the retina appeared to be controlled only by light. The clones of chicken AANAT and HIOMT genes that we have isolated should help us to understand the molecular mechanisms of: 1) their transcriptional regulation by circadian oscillators and by light; 2 ) their tissue-specific expression in the pineal gland and the retina. $(\mathrm{C}$ Inra/ Elsevier, Paris
\end{abstract}

melatonin / tryptophan hydroxylase / arylalkylamine $N$-acetyltransferase / hydroxyindole$O$-methyltransferase / pineal / retina

\footnotetext{
* Correspondence and reprints

E-mail: neurobio@campus.univ-poitiers.fr
} 
Résumé -. Voie de synthèse de la mélatonine : régulation circadienne des gènes codant pour les enzymes clés, dans la glande pinéale et la rétine de poulet. Les ARNm codant trois des enzymes de la voie de synthèse de la mélatonine (tryptophane hydroxylase (TPH), arylalkylamine $N$-acétyltransférase (AANAT) et hydroxyindole- $O$-méthyltransférase (HIOMT)) sont exprimés selon un rythme jour/nuit, dans l'organe pinéal et la rétine de poulet. Les taux d'ARNm de la TPH et de l'AANAT sont maximum pendant la nuit. Le pic du taux d'ARNm de l'HIOMT est atteint de nuit dans la rétine, mais de jour dans l'organe pinéal. Dans ce tissu, les rythmes des taux d'ARNm de la TPH, de l'AANAT et de l'HIOMT persistent à l'obscurité constante (DD), à la fois in vivo et in vitro, ce qui suggère qu'ils sont contrôlés par l'oscillateur circadien de l'organe pinéal de Poulet. Dans la rétine, les rythmes des taux d'ARNm de la TPH et de l'AANAT persistent également en DD, in vivo, ce qui indique qu'ils sont sous contrôle d'un oscillateur circadien. Par contre, le rythme d'ARNm de l'HIOMT dans la rétine semble contrôlé uniquement par la lumière. Les clones des gènes de l'AANAT et de l'HIOMT de poulet, que nous avons isolés, devraient aider à comprendre les mécanismes moléculaires : 1) de leur régulation transcriptionnelle, par les oscillateurs circadiens et par la lumière ; 2) de la spécificité tissulaire de leur expression, dans l'organe pinéal et la rétine. (C) Inra/ Elsevier, Paris

mélatonine / tryptophane hydroxylase / arylalkylamine $N$-acetyltransferase / hydroxyindole$O$-methyltransferase/ pinéale/ rétine

\section{INTRODUCTION}

The production of the pineal hormone melatonin shows a daily rhythm with a nocturnal peak. The duration of this peak reflects the duration of the night and provides temporal information to the organism. This melatonin rhythm influences many physiological functions, including locomotor activity and reproduction $[1,17,35]$. The main source of circulating melatonin is the pineal gland. However, melatonin is also produced in the retina where it seems to act mainly as a local modulator of neuronal activity and photoreceptor metabolism [5, $34,44]$.

The rhythm of melatonin production in the pineal is not merely driven by the light/dark cycle, but is controlled by an endogenous mechanism. In birds, at least two circadian clocks are involved in this control: one is located in the visual suprachiasmatic nuclei and influences pineal melatonin production through sympathetic innervation $[11,12]$; another one is located in the pineal gland itself $[8,16]$. In vivo experiments have suggested the presence of yet another circadian oscillator in the chicken retina that would control local melatonin production [43]; however, in vitro experiments confirming this point are still needed. The existence of a retinal clock controlling melatonin production has been demonstrated in vitro for Xenopus [6, 10], zebrafish [9], hamster [39] and mouse [40]. Day/night changes in mRNA levels have been observed, in both the pineal gland and the retina, for three of the enzymes of the melatonin biosynthesis pathway: tryptophan hydroxylase (TPH, E.C.1.14.16.4), which converts tryptophan to 5-hydroxytryptophan, arylalkylamine$N$-acetyltransferase (AANAT, E.C.2.3.1.87), which converts 5-hydroxytryptamine (serotonin) to $N$-acetyl-5-hydroxytryptamine $(N$-acetylserotonin) and hydroxyindole$O$-methyltransferase (HIOMT, E.C.2.1.1.4), which converts $\mathrm{N}$-acetylserotonin to melatonin. The transcriptional regulation of AANAT generates a corresponding rhythm of AANAT enzyme activity [3], which appears to be responsible for the rhythm in melatonin production, in the pineal gland and the retina. The rhythm in TPH mRNA levels $[14,19,29]$ is followed by a lowamplitude rhythm of TPH enzyme activity in the retina [38] and of TPH neosynthesis in the pineal gland [18]. HIOMT enzyme activ- 
ity only shows $20 \%$ changes throughout the light/dark cycle in the chicken pineal gland [7] and no clear-cut day/night changes in the retina (Bernard M., Voisin P., unpublished results). However, the mRNA encoding this enzyme is expressed with a daily rhythm of significantly greater amplitude, in the chicken pineal gland and retina [2, $30,31]$. In the present paper, our purpose is to compare the patterns of rhythmic transcription of these three genes and to delineate the contributions of clock- versus lightregulated mechanisms in the control of these rhythms in the chicken pineal gland and retina.

\section{RHYTHMS OF TPH, AANAT AND HIOMT mRNAs IN THE CHICKEN PINEAL GLAND}

Two forms of TPH mRNA are detected in the pineal gland: a major transcript of $\sim 4 \mathrm{~kb}$ and a minor one of $\sim 3.5 \mathrm{~kb}$. In chickens raised under a light/dark cycle (LD), these two forms of TPH mRNA show a day/night rhythm with a peak in the early dark phase (between ZT12 and ZT18) (figure $I A$, see also [19]). The TPH mRNA levels are increased about 6-fold at night as compared to the daytime levels. A similar pattern of oscillation is observed for the single AANAT transcript (1.6 kb), although it reaches its peak slightly later than the TPH mRNA, between ZT15 and ZT21 (figure IC). The amplitude of the nocturnal increase in AANAT mRNA is about 9-fold. The situation is clearly different for HIOMT, because the rhythm of its mRNA is 180 degrees out of phase with those of TPH and AANAT mRNAs, i.e. the peak of HIOMT mRNA (single transcript of $1.6 \mathrm{~kb}$ ) occurs in the middle of the light phase (figure $1 E$ ). The difference between midday and midnight levels of HIOMT mRNA is about 3-fold. It should be noted here that this pattern seems characteristic of the chicken pineal gland, because similar studies performed in the rat have shown a rhythm in HIOMT mRNA with a nocturnal peak [23].
The rhythms in TPH, AANAT and HIOMT mRNA levels in the chicken pineal are not just passive responses to the light/dark cycle, because they all persist when the animals are maintained in constant darkness (DD) $[3,14,30]$. The rhythms of TPH and AANAT mRNA are also observed in the pineals of chickens raised in constant light (LL) $[3,14]$; this type of study has not been performed for HIOMT. The persistence of these rhythms in constant lighting conditions (DD or LL) indicates that these three genes are controlled by a circadian clock. Because the chicken pineal gland contains its own oscillator $[8,16]$, the next question to ask was whether this pineal oscillator was the one involved in the rhythmic expression of the TPH, AANAT and HIOMT genes. To answer this question, the levels of mRNAs transcribed from these three genes were analyzed in vitro and in constant darkness. These experiments revealed that the rhythmicity of TPH, AANAT and HIOMT mRNA levels also persisted under these conditions: the TPH and AANAT mRNA levels peaked during the subjective night $([19,29]$ and figure $2 A)$, whereas HIOMT mRNA levels peaked during the subjective day (figure $2 B$ ). These in vitro studies clearly demonstrated the role of the pineal oscillator in generating the rhythms of TPH, AANAT and HIOMT mRNA levels. However, in vivo as well as in vitro, the amplitude of the rhythms in TPH, AANAT and HIOMT mRNA levels was lower in DD than in LD. The damping of the rhythms in TPH and AANAT mRNA levels is mainly due to higher values in the subjective day than in the effective day [3, 141, while the damping of the HIOMT mRNA rhythm is mainly due to lower values in the subjective day than in the effective day [30]. This observation suggests that, although light is not required for rhythmic transcription, it contributes to the maintenance of low levels of TPH and AANAT mRNAs and high levels of HIOMT mRNA during the daytime. It is not known whether this effect of light is mediated through the 


\section{Pineal}

A.

Zeitgeber Time (hr)
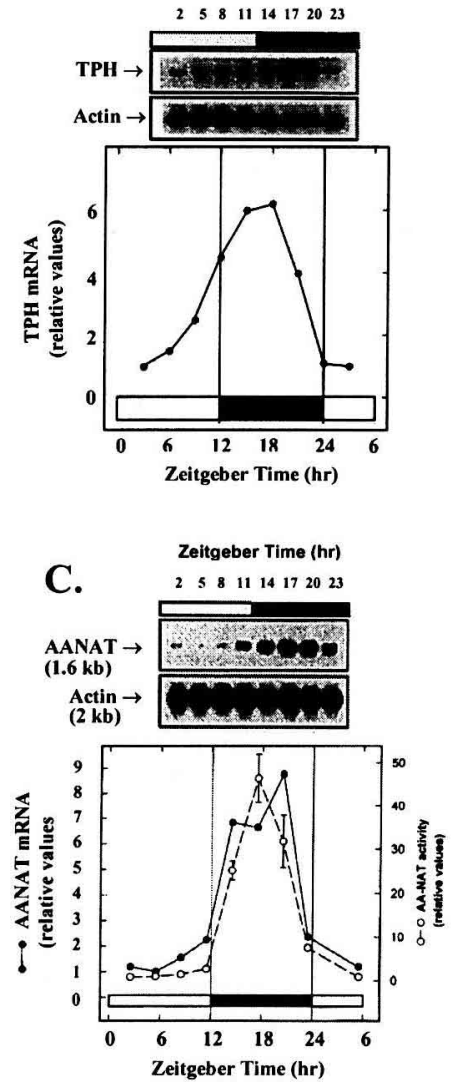

E.

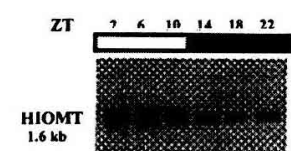

Actin

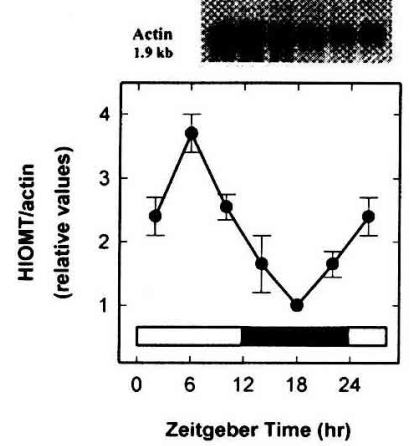

B.

\section{Retina}

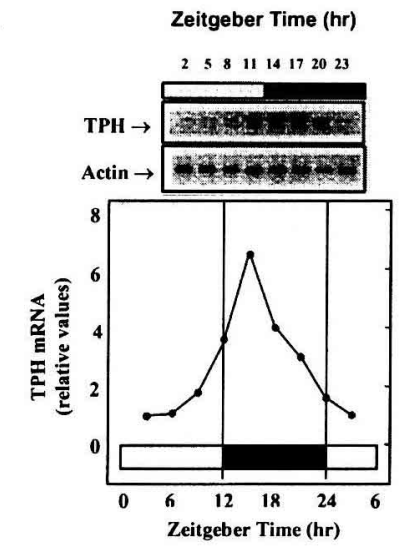

D.

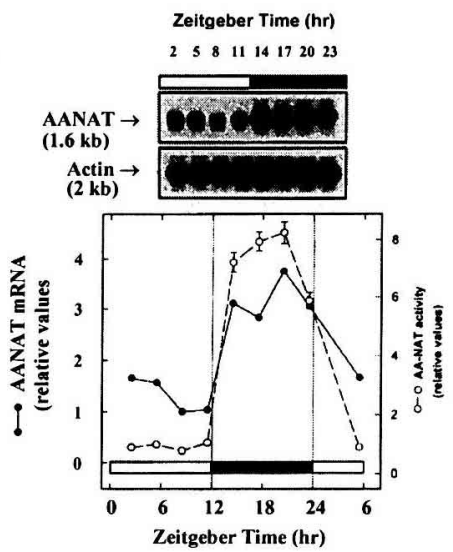

F.
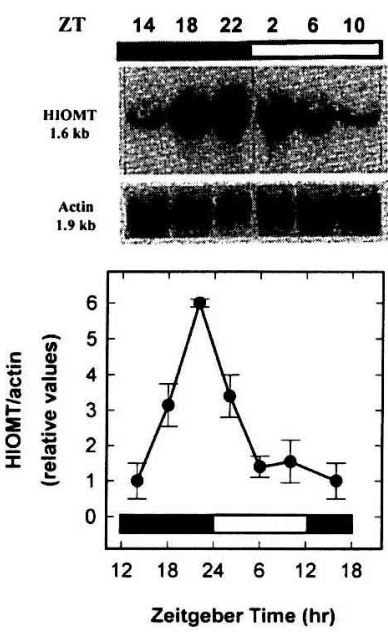
circadian clock (entrainment) or if it reflects a direct response to the phototransduction mechanism.

\section{RHYTHMS OF TPH, AANAT AND HIOMT mRNAs IN THE CHICKEN RETINA}

The mRNAs encoding TPH, AANAT and HIOMT are also expressed with a day/night rhythm in the chicken retina. For $\mathrm{TPH}$, this rhythm in mRNA is very similar to the one observed in the pineal gland: the levels of the two transcripts increase about 6-fold during the night, with a peak around ZT 15 (figure $1 B$ ). The rhythm in retinal AANAT mRNA is also similar to the one in the pineal gland, with maximum levels during the dark phase, between ZT 15 and ZT21. The amplitude of the nocturnal increase is, however, lower (4-fold) than in the pineal gland (figure $1 D$ ). The mRNA encoding HIOMT is expressed with a day/night rhythm in the retina but, in contrast to the pineal gland, the mRNA levels peak in the late dark phase (ZT22) and gradually decrease during the light phase (figure $l F$ ). The average difference between day and night levels (5-fold) is greater than in the pineal gland [31].

The oscillations in TPH and AANAT mRNAs are still observed in the retina of chickens maintained in DD or in LL [3, 14], indicating that in this tissue, as in the pineal gland, the expression of the two genes is influenced by a circadian oscillator. The question of whether this oscillator is located within the retinal photoreceptor cells has not been addressed directly by culturing chicken retinal cells in DD. Instead, retinas were injected with kainic acid, in vivo, to destroy most of the inner retina. This treatment, which apparently leaves the photoreceptor cells undamaged, does not affect the TPH [14] or the AANAT mRNA rhythm (Bernard M., Klein D., Iuvone M., unpublished data) in LD. However, endogenous rhythmicity (in DD or LL) after kainate treatment has not been reported. For both TPH and AANAT mRNAs, the amplitude of the rhythms in DD or LL is markedly reduced as compared to the one observed in LD (3-fold increase instead of 6-fold for TPH, 1.5- to 2-fold instead of 4-fold for AANAT). This suggests that, in the retina, the rhythmicity of TPH and AANAT mRNA levels is more dependent upon the light/dark cycle than in the pineal gland. The rhythm in retinal HIOMT mRNA levels has not been studied in DD or LL conditions. However, the question of a possible control by a circadian oscillator has been addressed using a similar approach, for example by extending the dark phase or the light phase by $10 \mathrm{~h}$. The nocturnal rise in HIOMT mRNA levels did not occur in the presence of light and conversely, the diurnal decrease did not occur in the absence of light [31]. The absence of a photorefractory period in this retinal HIOMT mRNA rhythm suggests that it is not driven by a circadian clock, but occurs only as a passive response to an inhibitory effect of light (figure $1 F$ ). Altogether, these results suggest that light

Figure 1. Chickens were housed in a light/dark cycle (LD 12:12; lights on at zeitgeber time (ZT) 0 ). The solid bars indicate when lights were off. Pineal glands $(\mathbf{A}, \mathbf{C}$ and $\mathbf{E})$ and retinas $(\mathbf{B}, \mathbf{D}$ and $\mathbf{F})$ were taken at the indicated times and processed for RNA analysis. Top panels: representative northern blot analyses of TPH (A and B), AANAT (C and D), HIOMT (E and F) and actin mRNAs. Bottom panels: quantitative analysis of the northern blots $(\mathbf{O}: \mathrm{A}-\mathrm{F})$ and levels of AANAT activity $(\mathrm{O}: \mathrm{C}$ and $\mathrm{D})$ in each experimental group. The abundance of TPH, AANAT and HIOMT transcripts has been normalized to actin mRNA, to correct for variations in loading. Data are means of duplicate determinations $( \pm$ SD in panels $\mathrm{E}$ and $\mathrm{F}$ ) and are expressed relative to the values at ZT2 (A and B), ZT5 (C), ZT8 (D), ZT 18 (E) or ZT12 (F). (Panels A and B are from [14]; panels C and D are from [3]; panel E is from [29]; panel $\mathrm{F}$ is from [30].) 
A.

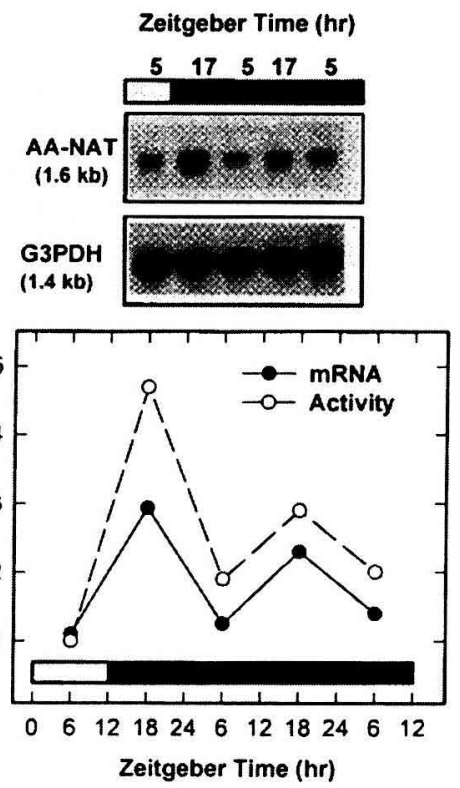

B. Zeitgeber Time (hr)
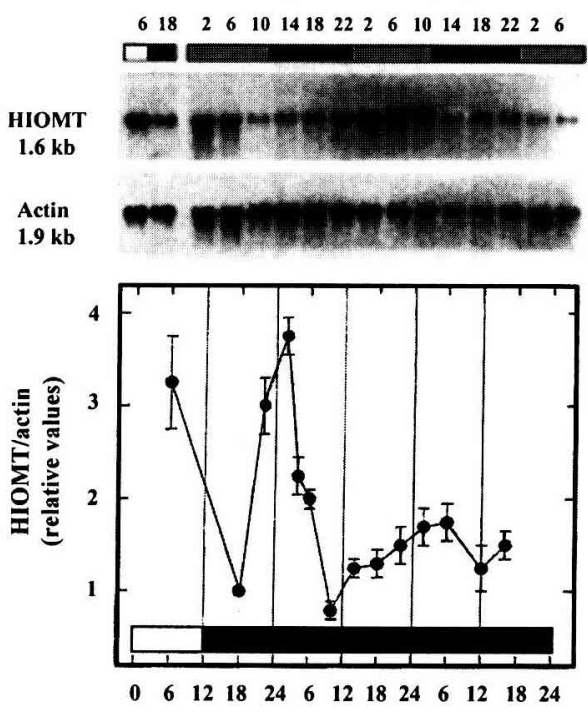

Zeitgeber Time ('hr)

Figure 2. A) Dissociated pineal cells from 1-day-old chicks were cultured for 4 days in a light/red cycle (LR 12:12; white lights on at ZT0) and were transferred to constant red (RR). The filled bar indicates when white light was off. Cells were harvested at the indicated times (zeitgeber times are indicated as a reference). The top panel shows a representative northern blot analysis of AANAT and glyceraldehyde-3-phosphate-dehydrogenase (G3PDH) mRNAs. The bottom panel illustrates the quantitative analysis of the northern blot, after normalization to the G3PDH signal (), and the levels of AANAT activity $(O)$ at each time point. Values represent the mean of duplicate determinations and are expressed relative to the first ZT5 time point. (From [4].) B) One-day-old chicks were kept for 4 days in a light/dark cycle (LD 12:12; lights on at ZT0). Pineal glands were taken in the morning of the 4th day and were cultured for 3 days under the same lighting schedule. On the 4th day of culture, pineals were placed in constant darkness (black and grey horizontal bars) and were collected at the indicated time points. The top panel shows a representative northern blot analysis of HIOMT and actin mRNAs. The bottom panel is a quantitative analysis of the northern blot, after normalization to the actin signal. Values represent the mean of duplicate determinations $( \pm S D)$ and are expressed relative to the first ZT18 time point. (From [29].)

has a major influence on gene expression in the retina, an influence that may, in some cases (HIOMT), overrule that of the clock. The stronger effect of light in the retina than in the pineal is also indicated by in vivo experiments showing that acute exposure to light at night causes a small, but significant, decrease in AANAT and TPH mRNA levels in the retina, but does not affect the levels of these transcripts in the pineal gland $[3,14]$.

\section{ELUCIDATING THE MOLECULAR MECHANISMS OF LIGHT- AND CLOCK-CONTROLLED TRANSCRIPTIONAL REGULATION}

We have recently cloned the genes and the promoter regions of the chicken HIOMT [25] and AANAT (Bernard M., Chong N.W., Klein D.C., unpublished results). These clones should now help to elucidate the mechanisms of the transcriptional regulation of HIOMT and AANAT. Over the 
years, models have been proposed to explain how transcription factors could generate an endogenous rhythm of gene expression. One of these models was based on the regulation by cAMP-dependent transcription factors. The key actor in this regulation was the inhibitory transcription factor ICER (inducible cAMP early repressor), which is expressed under control of a cAMPinducible promoter, located in an intronic region of the CREM (cAMP regulatory element modulator) gene [37]. The model proposed was that of a negative autoregulatory loop, initiated by the instability of the intracellular level of cAMP [36]: a rise in cAMP levels, subsequent to the activation of transmembrane receptors, can activate stimulatory transcription factors such as CREB, which increases the transcriptional level of cAMP-dependent genes, but it also causes the expression of ICER, which represses the transcription of these genes. The postulate was that, when the ICER protein accumulated, it inhibited its own expression, therefore releasing the repression and allowing a new cycle of transcriptional activation. Although attractive, this model could not account for a self-sustained rhythmicity of transcription, because it was dependent upon the increase in intracellular cAMP levels. In addition, this mechanism of gene regulation by ICER was first demonstrated in the rat pineal gland, an organ which does not contain any circadian oscillator. Some evidence suggest that, in the rat pineal gland, ICER could control the shape and the amplitude of the AANAT mRNA rhythm in response to the adrenergic signal [20]. However, it does not seem to be a key element in the genesis of this rhythm, because the rhythmic transcription of AANAT persists in CREM-knockout mice [20]. In the avian pineal gland, which does contain a circadian oscillator, the contribution of cAMP in the clock mechanism has not received any experimental support. In cultured chick pineal cells, agents which alter the intracellular levels of cAMP are not able to phaseshift the rhythm of melatonin and do not interfere with the phase-shift induced by light pulses [41, 42]. In addition, it seems unlikely that the circadian expression of the AANAT or TPH genes in the chicken pineal gland relies on a cAMP-dependent mechanism, because the transcription of these genes is only moderately increased $(20-50 \%)$ by cAMP [3, 29]. The expression of HIOMT mRNA in the chicken pineal gland is increased 2- to 3-fold in response to elevated cAMP levels [26]. This regulation by cAMP does not appear to be required for the day/night rhythmicity of the HIOMT transcript [26], but it might be able to influence the basal level of HIOMT gene transcription. To conclude on the role of cAMP, it should be noted that what is true for the chicken pineal gland may not be a general rule. Recent studies on the Xenopus retina have shown that the circadian oscillator located in this tissue is phase-shifted by variations in cAMP levels [32]. Xenopus retina may therefore provide a valuable model system to analyze the connection between cAMP and circadian rhythms of transcription.

The major alternative model of the circadian oscillator was based on the transcriptional control by a 'clock gene'. The starting hypothesis was that this gene should encode a transcription factor which could sustain its own rhythmic expression, through a negative feedback loop, but could also control the rhythmic transcription of other target genes. Several candidates meeting these criteria had been identified in $\mathrm{Neu}$ rospora crassa (Frq) and in Drosophila (Per and Tim) $[27,33]$. This 'clock gene' model has recently received extensive support from several laboratories, but has also increased in complexity [28]. The emerging picture is based on the action of at least four nuclear proteins organized as heterodimers. The first heterodimer is composed of two basic helixloop-helix (bHLH) transcription factors, with PAS interaction domains: CLOCK and BMAL1. The CLOCK-BMAL1 heterodimer is a transcriptional activator, which binds to E-box elements (CACGTG) in the pro- 
moter regions of two genes encoding PAScontaining proteins, Per and Tim [24]. Following the activation of transcription, these two proteins accumulate and form another heterodimer, which blocks the transcriptional activation by CLOCK-BMAL1 (possibly by sequestering this last heterodimer) [15]. The subsequent decrease in the expression of Per and Tim releases the CLOCKBMAL1 heterodimer, which can again activate transcription and reinitiate a new loop. As CLOCK-BMAL1 activates transcription by binding to E-box elements, we looked for the presence of such motifs in the HIOMT and AANAT promoters. Although 16 E-box sequences (CANNTG) are found in the HIOMT promoter (figure $3 B$ ), none of them matches the exact motif CACGTG that appears to be required for transcrip- tional activation by CLOCK-BMAL1. In contrast, one such element is present in the proximal promoter region of the chicken AANAT gene (figure $3 A$ ). The functional analysis of this promoter should help to determine whether this potential CLOCKBMAL1 binding site plays a role in the rhythmic transcription of the chicken AANAT gene. The analysis of the HIOMT promoter should also be of special interest, because it conveys circadian transcription in the pineal gland, but not in the retina, thus allowing comparative studies between the two tissues. One way to perform these functional studies will be to test the ability of the chicken AANAT and HIOMT promoters (complete or partially deleted) to drive the circadian transcription of a reporter gene, in transfected pineal (or retinal) cells.

\section{A. Aanat}

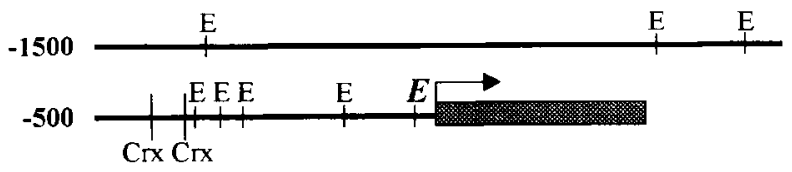

\section{B. HIOMT}

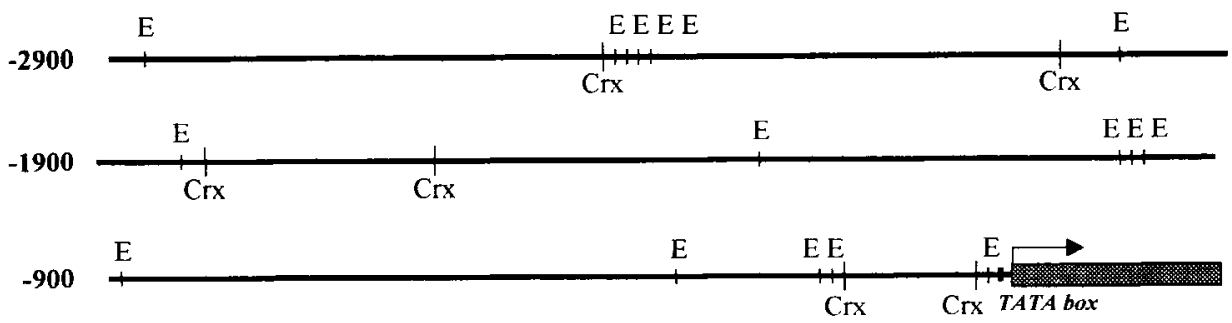

Figure 3. Schematic representation of the chicken AANAT (A) and HIOMT (B) promoters. The shaded boxes with an arrow represent the first exon of the genes. The letter ' $E$ ' shows the positions of the E-box sequences; the letter ' $\mathrm{E}$ ' in bold and italic shows the position of the potential binding site for CLOCK-BMALl in the AANAT promoter. 'Crx' indicates the positions of the potential binding sites for the photoreceptor-specific transcription factor $\mathrm{Crx}$. The unusual 'TATA-box' of the HIOMT promoter [25] is also indicated. 
Sequence analyses of the AANAT and HIOMT promoters have also revealed the presence of potential binding sites for the newly identified photoreceptor-specific transcription factor Crx (cone-rod homeoboxcontaining protein) (figure 3). This transcription factor is expressed only in the pineal gland and the retina [13] and seems to be required for the normal differentiation of photoreceptor cells $[21,22]$. Transfection experiments have shown that $\mathrm{Crx}$ can bind to and transactivate the promoter regions of photoreceptor-specific genes (rhodopsin, arrestin, interphotoreceptor retinoid-binding protein) [13]. However, these studies have been focused mainly on the role of Crx on the expression of genes of the phototransduction cascade. Because melatonin synthesis is another important characteristic of the functional diffentiation of photoreceptor cells, it would be of great interest to determine whether Crx can also play a role in the tissue-specific expression of the AANAT and HIOMT genes.

Together, the cloned promoter regions of the chicken AANAT and HIOMT genes should provide valuable models to identify cis-regulatory elements involved in circadian rhythmicity and in pineal/retina-specific gene transcription.

\section{REFERENCES}

[1] Arendt J., Melatonin and the Mammalian Pineal Gland, Chapman and Hall, London, 1995.

[2] Bernard M., Guerlotté J., Cogné M., Grève P., Collin J.P., Voisin P., Transcriptional regulation of hydroxyindole- $O$-methyltransferase in the chicken pineal gland: day/night changes and long-term effects of light and darkness, Biochem. J. 290 (1993) 661-664.

[3] Bernard M., Iuvone P.M., Cassone V.M., Roseboom P.H., Coon S.L., Klein D.C., Avian melatonin synthesis: photic and circadian regulation of serotonin $N$-acetyltransferase mRNA in the chicken pineal gland and retina, J. Neurochem. 68 (1997) 213-224.

[4] Bernard M., Klein D.C., Zatz M., Chick pineal clock regulates serotonin $N$-acetyltransferase mRNA rhythm in culture, Proc. Natl. Acad. Sci. USA 94 (1997) 304-309.
[5] Besharse J.C., Dunis D.A., Methoxyindoles and photoreceptor metabolism: activation of rod shedding, Science 219 (1983) 1341-1343.

[6] Besharse J.C., Iuvone P.M., Circadian clock in Xenopus eye controlling retinal serotonin $N$-acetyltransferase, Nature 305 (1983) 133-135.

[7] Binkley S.A., MacBride S.E., Klein D.C., Ralph C.L., Pineal enzymes: regulation of avian melatonin synthesis, Science 181 (1973) 273-275.

[8] Binkley S.A., Riebman J.B., Reilly K.B., The pineal gland: a biological clock in vitro, Science 202 (1978) 1198-1201.

[9] Cahill G.M., Circadian regulation of melatonin production in cultured zebrafish pineal and retina, Brain Res. 708 (1996) 177-181.

[10] Cahill G.M., Besharse J.C., Circadian clock functions localized in Xenopus retinal photoreceptors, Neuron 10 (1993) 573-577.

[11] Cassone V.M., Menaker M., Sympathetic regulation of chicken pineal thythms, Brain Res. 272 (1983) 311-317.

[12] Cassone V.M., Forsyth A.M., Woodlee G.L., Hypothalamic regulation of circadian noradrenergic input to the pineal gland, J. Comp. Physiol. [A] 167 (1990) 187-192.

[13] Chen S., Wang Q.L., Nie Z., Sun H., Lennon G., Copeland N.G., Gilbert D.J., Jenkins N.A., Zack D.J., Crx, a novel otx-like paired-homeodomain protein, binds to and transactivates photoreceptor cell-specific genes, Neuron 19 (1997) 1017-1030.

[14] Chong N.W., Cassone V.M., Bernard M., Klein D.C., Iuvone P.M., Circadian expression of tryptophan hydroxylase $\mathrm{mRNA}$ in the chicken retina, Mol. Brain Res. 61 (1998) 243-250.

[15] Darlington T.K., Wager-Smith K., Ceriani M.F., Staknis D., Gekakis N., Steeves T.D.L., Weitz C.J., Takahashi J.S., Kay S.A., Closing the circadian loop: CLOCK-induced transcription of its own inhibitors per and tim, Science 280 (1998) 1599-1603.

[16] Deguchi T., A circadian oscillator in cultured cells of chicken pineal gland, Nature 282 (1979) 94-96.

[17] Dollins A.B., Zhdanova I., Wurtman R.J., Lynch H.J., Deng M.H., Effect of inducing nocturnal serum melatonin concentrations in daytime on sleep, mood, body temperature, and performance, Proc. Natl. Acad. Sci. USA 91 (1994) 1824-1828.

[18] Florez J.C., Takahashi J.S., Quantitative twodimensional gel electrophoretic analysis of clock-controlled proteins in cultured chick pineal cells: circadian regulation of tryptophan hydroxylase, J. Biol. Rhythms 11 (1996) 241-257.

[19] Florez J.C., Seidenman K.J., Barrett R.K., Sangoram A.M., Takahashi J.S., Molecular cloning of chick pineal tryptophan hydroxylase and circadian oscillation of its mRNA levels, Mol. Brain Res. 42 (1996) 25-30. 
[20] Foulkes N.S., Borjigin J., Snyder S.H., SassoneCorsi P., Transcriptional control of circadian hormone synthesis via the CREM feedback loop, Proc. Natl. Acad. Sci. USA 93 (1996) 14140-14145.

[21] Freund C.L., Gregory-Evans C.Y., Furukawa T., Papaioannou M., Looser J., Ploder L., Bellingham J., Ng D., Herbrick J.A.S., Duncan A., Scherer S.W., Tsui L.C., Loutradis-Anagnostou A., Jacobson S.G., Cepko C.L., Bhattacharya S.S., McInnes R.R., Cone-rod dystrophy due to mutations in a novel photoreceptor-specific homeobox gene ( $\mathrm{Cr} x$ ) essential for maintenance of the photoreceptor, Cell 91 (1997) 543-553.

[22] Furukawa T., Morrow E.M., Cepko C.L., Crx a novel ot $x$-like homeobox gene, shows photoreceptor-specific expression and regulates photoreceptor differentiation, Cell 91 (1997) 531-541.

[23] Gauer F., Craft C.M., Circadian regulation of hydroxyindole- $O$-methyltransferase mRNA levels in rat pineal and retina, Brain Res. 737 (1996) 99-109.

[24] Gekakis N., Staknis D., Nguyen H.B., Davis F.C., Wilsbacher L.D., King D.P., Takahashi J.S., Weitz C.J., Role of CLOCK protein in the mammalian circadian mechanism, Science 280 (1998) 1564-1569.

[25] Gréchez-Cassiau A., Bernard M., Ladjali K., Rodriguez I.R., Voisin P., Structural analysis of the chicken hydroxyindole- $O$-methyltransferase gene, Eur. J. Biochem. 258 (1998) 44-52.

[26] Gréchez-Cassiau A., Grève P., Guerlotté J., Voisin P., Cyclic AMP increases hydroxyindole- $O$-methyltransferase mRNA levels in the chicken pineal gland, but is not required for circadian rhythmicity of this transcript, Brain Res. (1999) in press.

[27] Green C.B., How cells tell time, Trends Cell Biol. 8 ( 1998) 224-230.

[28] Green C.B., Time marches on, Trends Cell. Biol. 8 (1998) 342-343.

[29] Green C.B., Besharse J.C., Zatz M., Tryptophan hydroxylase mRNA levels are regulated by the circadian clock, temperature, and cAMP in chick pineal cells, Brain Res. 738 (1996) 1-7.

[30] Grève P., Voisin P., Grechez-Cassiau A., Bernard M., Collin J.P., Guerlotté J., Circadian regulation of hydroxyindole- $O$-methyltransferase mRNA in the chicken pineal gland in vivo and in vitro, Biochem. J. 319 (1996) 761-766.

[31] Guerlotté J., Grève P., Bernard M., GrechezCassiau A., Morin F., Collin J.P., Voisin P., Hydroxyindole- $O$-methyltransferase in the chicken retina: immunocytochemical localization and daily rhythm of mRNA, Eur. J. Neurosci. 8 (1996) $710-715$.
[32] Hasegawa M., Cahill G.M., Cyclic AMP resets the circadian clock in cultured Xenopus retinal photoreceptor layers, J. Neurochem. 70 (1998) 1523-1531.

[33] Hastings M.H., Central clocking, TINS 20 (1997) 459-463.

[34] Iuvone P.M., Cell biology and metabolic activity of photoreceptor cells: light-evoked and circadian regulation, in: Djamgoz M.B.A., Archer S., Vallerga S. (Eds.), Neurobiology and Clinical Aspects of the Outer Retina, Chapman and Hall, London, 1995, pp. 25-55.

[35] Karsh F.J., Woodfill C.J.I., Malpaux B., Robinson J.E., Wayne N.L., Melatonin and mammalian photoperiodism: synchronization of annual reproductive cycles, in: Klein D.C., Moore R.Y., Reppert S.M. (Eds.), Suprachiasmatic Nucleus: the Mind's Clock, Oxford University press, New York, 1991, pp. 217-232.

[36] Molina C.A., Foulkes N.S., Lalli E., SassoneCorsi P., Inducibility and negative autoregulation of CREM: an alternative promoter directs the expression of ICER, an early response repressor, Cell 75 (1993) 875-886.

[37] Stehle J.H., Foulkes N.S., Molina C.A., Simonneaux V., Pévet P., Sassone-Corsi P., Adrenergic signals direct rhythmic expression of transcriptional repressor CREM in the pineal gland, Nature 365 (1993) 314-320.

[38] Thomas K.B., Iuvone P.M., Circadian rhythm of tryptophan hydroxylase activity in chicken retina, Cell Mol. Neurobiol. 11 (1991) 511-527.

[39] Tosini G., Menaker M., Circadian rhythms in cultured mammalian retina, Science 272 (1996) 419-421.

[40] Tosini G., Menaker M., The clock in the mouse retina: melatonin synthesis and photoreceptor degeneration, Brain Res. 789 (1998) 221-228.

[41] Zatz M., Mullen D.A., Norepinephrine, acting via adenylate cyclase, inhibits melatonin output but does not phase-shift the pacemaker in cultured chick pineal cells, Brain Res. 450 (1988) 137-143.

[42] Zatz M., Mullen D.A., Photoendocrine transduction in cultured chick pineal cells. II. Effects of forskolin, 8-bromocyclic AMP, and 8-bromocyclic GMP on the melatonin rhythm, Brain Res. 453 (1988) 51-62.

[43] Zawilka J.B., Iuvone P.M., Melatonin synthesis in chicken retina: effect of kainic acid-induced lesions on the diurnal rhythm and $\mathrm{D}_{2}$-dopamine receptor-mediated regulation of serotonin $\mathrm{N}$-acetyltransferase activity, Neurosci. Lett. 135 (1992) 71-74.

[44] Zawilska J.B., Nowak J.Z., Regulatory mechanisms in melatonin biosynthesis in retina, Neurochem. Int. 20 (1992) 23-36. 